Bond University

Research Repository

\title{
Novel insights into the mechanism of cyclophosphamide-induced bladder toxicity: chloroacetaldehyde's contribution to urothelial dysfunction in vitro
}

Mills, Kylie A; Chess-Williams, Russ; McDermott, Catherine

Published in:

Archives of Toxicology

DOI:

10.1007/s00204-019-02589-1

Licence:

Other

Link to output in Bond University research repository.

Recommended citation(APA):

Mills, K. A., Chess-Williams, R., \& McDermott, C. (2019). Novel insights into the mechanism of

cyclophosphamide-induced bladder toxicity: chloroacetaldehyde's contribution to urothelial dysfunction in vitro. Archives of Toxicology, 93(11), 3291-3303. https://doi.org/10.1007/s00204-019-02589-1

\section{General rights}

Copyright and moral rights for the publications made accessible in the public portal are retained by the authors and/or other copyright owners and it is a condition of accessing publications that users recognise and abide by the legal requirements associated with these rights.

For more information, or if you believe that this document breaches copyright, please contact the Bond University research repository coordinator. 


\title{
Novel insights into the mechanism of
}

\author{
cyclophosphamide induced bladder toxicity:
}

\section{chloroacetaldehyde's contribution to urothelial}

\section{dysfunction in vitro}

\author{
Kylie A. Mills ${ }^{1}$, Russ Chess-Williams ${ }^{1}$ \& Catherine McDermott $^{1}$ \\ ${ }^{1}$ Centre for Urology Research, Faculty of Health Sciences and Medicine, Bond University \\ Gold Coast, Queensland, Australia 4229
}

Corresponding Author: Dr Catherine McDermott, Centre for Urology Research, Faculty of Health Sciences and Medicine, Bond University Gold Coast, Queensland, Australia 4229. camcderm@bond.edu.au (+61 755954777$)$ 


\section{Abstract}

The clinical use of cyclophosphamide and ifosfamide is limited by a resultant bladder toxicity which has been attributed to the metabolite acrolein. Another metabolite chloroacetaldehyde (CAA) associated with nephrotoxicity, has not been investigated for toxicity in the bladder and this study investigates the effects of acrolein and CAA on human urothelial cells in vitro. Human urothelial cells (RT4 and T24) were treated with acrolein or CAA and changes in cell viability, reactive oxygen species, caspase-3 activity and release of urothelial mediators ATP, acetylcholine, $\mathrm{PGE}_{2}$ were measured. The protective effects of $\mathrm{N}$-acetyl cysteine (NAC) were also assessed. Both metabolites were toxic to human urothelial cells however, CAA significantly decreased cell viability at a 10 -fold lower concentration $(10 \mu \mathrm{M})$ than acrolein $(100 \mu \mathrm{M})$. This was associated with increased ROS production and caspase-3 activity. NAC protected cells from these changes. In RT4 cells $100 \mu \mathrm{M}$ acrolein caused a significant increase in basal and stretch-induced ATP, Ach and $\mathrm{PGE}_{2}$ release. In T24 cells chloroacetaldehyde $(10 \mu \mathrm{M})$ increased basal and stimulated ATP and $\mathrm{PGE}_{2}$ levels. Again, NAC protected against changes in urothelial mediator release following acrolein or CAA. This study is the first to report that CAA in addition to acrolein contributes to the urotoxicity of cyclophosphamide and ifosfamide. Both metabolites altered urothelial mediator levels which could contribute to the sensory and functional bladder changes experienced by patients after treatment with cyclophosphamide or ifosfamide. Alterations in urothelial cell viability and mediator release may be causally linked to oxidative stress, with NAC providing protection against these changes.

Keywords: Cyclophosphamide, chloroacetaldehyde, acrolein, ifosfamide, urothelium, urotoxicity, oxidative stress, $\mathrm{N}$-acetyl cysteine 


\section{Introduction}

Cyclophosphamide and ifosfamide are common chemotherapeutic and immunosuppressive agents extensively used in the treatment of numerous cancers and chronic autoimmune disorders (Lawson et al. 2008). A major limiting factor in the use of cyclophosphamide and ifosfamide is their bladder toxicity which can result in life threatening hemorrhagic cystitis (Coggins et al. 1960; Korkmaz et al. 2007). This toxicity limits the dose and frequency of administration of these drugs and hence the full efficacy of these drugs and their clinical outcomes may not be fully realised. Even after the adoption of co-administering the water soluble anti-oxidant mesna as a uroprotective agent, a high incidence of bladder toxicity is still observed with severe hematuria being reported in up to $10 \%$ of patients receiving these drugs for cancer treatment (Fukuoka et al. 1991). In addition, patients can experience lasting side effects such as pain when urinating, frequency and pelvic pain which affect their ongoing quality of life (Fukuoka et al. 1991). As a result of these common urotoxic effects, cyclophosphamide and ifosfamide are also frequently used in experimental models to induce cystitis (Aronsson et al. 2012; Deberry et al. 2014; Golubeva et al. 2014).

Ifosfamide is more toxic than cyclophosphamide and its metabolism favours detoxification over therapeutic activation requiring a dose double that of cyclophosphamide to produce a similar concentration of active drug (Lawson et al. 2008). The metabolite acrolein is produced during activation of both cyclophosphamide and ifosfamide and it is almost exclusively blamed for the urotoxicity of these drugs. Acrolein is excreted in the urine and as a result comes into direct contact with the urothelium (Al-Rawithi et al. 1998; Brock et al. 1979) which is an important regulator of bladder function (Birder and Andersson 2013). However, another toxic metabolite excreted in the urine is chloroacetaldehyde (CAA) which is produced during detoxification of both cyclophosphamide and ifosfamide. CAA has been linked to the neuro-, 
cardio- and nephro-toxicity of these drugs (Goren et al. 1986; Joqueviel et al. 1997; Sladek 1988) while its possible contribution to uro-toxicity has been ignored. Furthermore, these metabolites would be present in the urine together and their combined effects are yet to be investigated in the bladder. Very little is known about the actual concentrations of acrolein and CAA appearing in the urine of patients treated with cyclophosphamide and ifosfamide. One study has reported the peak concentration of acrolein in the urine of 19 patients receiving cyclophosphamide or ifosfamide as 100nM (Takamoto et al. 2004). While CAA concentrations up to $35 \mu \mathrm{M}$ have been measured in plasma (Pendyala et al. 2000), the urinary concentration has not yet been reported.

It has been suggested that the main mechanism by which acrolein causes bladder damage is through the production of reactive oxygen species (ROS) and nitric oxide (NO) (Korkmaz et al. 2007), resulting in lipid peroxidation, protein oxidation and DNA damage, depletion of nicotinamide adenine dinucleotide (NAD) and ATP ultimately causing necrotic cell death (Korkmaz et al. 2007). Acrolein can also bind to lysine, histidine and cysteine residues of proteins and nucleophilic sites in DNA resulting in widespread protein and DNA modification, potentially altering cell function (Beauchamp et al. 1985; Kehrer and Biswal 2000; Korkmaz et al. 2007). CAA toxicity has also been suggested to occur by similar mechanisms including depletion of cellular reduced glutathione, NAD and ATP, disturbed $\mathrm{Ca}^{2+}$ signalling, and lipid peroxidation, potentially leading to cell necrosis and death (Nissim et al. 2006; Schwerdt et al. 2006; Sood and O'Brien 1993).

Acrolein and CAA are excreted in the urine and therefore come into direct contact with the urothelium potentially altering bladder function or compromising the urothelial barrier allowing toxins to pass into the bladder wall. The urothelium functions as a physical barrier 
between the underlying cells and urine, but also plays important roles in regulating detrusor contraction (Hawthorn et al. 2000) and mechanosensation (Birder 2010). The urothelium responds to bladder filling by releasing chemical mediators such as ATP, acetylcholine (ACh), prostaglandin $\mathrm{E}_{2}\left(\mathrm{PGE}_{2}\right)$ and cytokines to communicate with underlying cells such as sensory nerves, interstitial cells and smooth muscle (Birder et al. 2010). Disruption of these mechanisms are associated with bladder dysfunction such as painful bladder syndrome/interstitial cystitis (Kumar et al. 2007) and bladder overactivity (Kumar et al. 2010) Therefore, this study aimed to investigate the effect of the cyclophosphamide and ifosfamide metabolites, acrolein and CAA, on the viability and function of human urothelial cells in vitro and determine if oxidative stress plays a causal role in the urotoxicity of these metabolites.

\section{Methods}

\section{Cell Culture}

RT4 and T24 cells were used in this study as a model of urothelial function. RT4 cells have been used previously as a model of urothelial mediator release (Kang et al. 2013b; Mansfield and Hughes 2014). Both cell lines were obtained from the European Collection of Cell Cultures (ECACC) and were grown and maintained at $37^{\circ} \mathrm{C}$ with $5 \% \mathrm{CO}_{2}$ in McCoy's $5 \mathrm{~A}$ culture medium (Invitrogen, Victoria, Australia) containing L-glutamine, phenol red, 10\% fetal bovine serum (FBS) and $500 \mathrm{U} / \mathrm{mL}$ penicillin-streptomycin (Invitrogen, Victoria, Australia). Cell viability was assessed by trypan blue exclusion.

Following seeding and incubation for $24 \mathrm{hrs,} \mathrm{cells} \mathrm{were} \mathrm{treated} \mathrm{with} \mathrm{cyclophosphamide} \mathrm{(0-}$ $100 \mu \mathrm{M})$, ifosfamide $(0-100 \mu \mathrm{M})$, acrolein $(0-100 \mu \mathrm{M})$, CAA $(0-10 \mu \mathrm{M})$ or a combination of acrolein $(100 \mathrm{nM})$ and CAA $(10 \mu \mathrm{M})$ in culture medium for a further $24 \mathrm{hrs}$. A matched control, which received culture medium only, was also examined during each experiment. To 
investigate the potential protective effects of $\mathrm{N}$-acetyl cysteine (NAC) cells were treated as described above but in the presence of NAC $(300 \mu \mathrm{M}$ and $1 \mathrm{mM})$. Cells were then ready for the following investigations.

\section{Resazurin proliferation assay}

Reduction of the redox dye resazurin to resorufin was used to measure the viability of cell cultures (Anoopkumar-Dukie et al. 2005). Cells were seeded at $1.35 \times 10^{4}$ trypan blueexcluding cells in $200 \mu 1$ of medium in 96 -well microtiter plates. Following drug treatment the medium above the cells was removed, wells were washed twice with phosphate buffered saline (PBS) and $200 \mu 1$ of fresh medium containing $44 \mu \mathrm{M}$ resazurin was added to each well. After optimum incubation ( $2 \mathrm{hr}$ or $1 \mathrm{hr}$ for RT4 and T24 cell lines respectively), reduction of resazurin to resorufin was determined by fluorescence (excitation 530nM; emission 590nM) using a Modulus Microplate Mulitmode Reader (Turner Biosystems, California, USA).

\section{DCFH-DA fluorimetry ROS assay}

Oxidation of DCF-DA (2',7'-Dichlorofluorescein diacetate) to dichlorofluorescein (DCF) was used to measure formation of reactive oxygen species by cell cultures. Following treatment the medium above the cells was removed, wells were washed twice with phosphate buffered saline and $100 \mu \mathrm{l}$ of fresh FBS-free medium containing $10 \mu \mathrm{M}$ DCFH-DA was added to each well. After 40 mins incubation oxidation of DCFH-DA to DCF was determined by fluorescence (excitation $485 \mathrm{nM}$; emission $535 \mathrm{nM}$ ) using a Modulus Microplate Mulitmode Reader. 
Measurement of Ach, ATP and PGE

Samples for measurement of basal and stretch-induced release of these urothelial mediators were generated as previously described (McDermott et al. 2012). Following $24 \mathrm{hr}$ treatment with the parent drugs or metabolites, incubation medium was aspirated and cells were washed twice with Krebs bicarbonate solution (118.4 mmol/L NaCl, 24.9 mmol $\mathrm{NaHCO}_{3}, 4.7 \mathrm{mmol}$ $\mathrm{KCl}, 1.9 \mathrm{mmol} \mathrm{CaCl}_{2}, 1.15 \mathrm{mmol} \mathrm{MgSO}_{4}, 1.15 \mathrm{mmol} \mathrm{KH}_{2} \mathrm{PO}_{4}$ and $11.7 \mathrm{mmol}$ glucose) prior to adding $150 \mu \mathrm{l}$ of Krebs bicarbonate solution to each well. After 15 mins, the solution in each well was removed for measurement of basal ACh, $\mathrm{ATP}$ and $\mathrm{PGE}_{2}$ release from treated and control RT4 or T24 cells. Next, $150 \mu$ l of hypotonic Krebs bicarbonate solution ( $50 \%$ of normal $\mathrm{NaCl}$ content) was applied to each well for 15 minutes. The use of hypotonic Krebs solution causes the cells to swell, mimicking the stretch that occurs during bladder filling. The solution in each well was collected for analysis of stimulated mediator release.

ACh release by urothelial cells was measured with an Amplex Red ACh/ACh esterase Assay Kit (Molecular Probes) and fluorescence measured using a Modulus Microplate Mulitmode Reader (Ex. 540 / Em. 590nm). ATP release was measured using a luciferase-luciferin ATP Determination Kit (Molecular Probes). The level of $\mathrm{PGE}_{2}$ released from cells was measured using Prostaglandin $E_{2}$ EIA Kit (Cayman Chemicals). The assays were performed according to manufacturer's protocols. Mediator concentrations in samples were calculated using standard curves constructed from known ACh, ATP or $\mathrm{PGE}_{2}$ standards. Concentrations of mediators measured were normalised to cell viability using corresponding resazurin reduction data. 
Caspase-3 activity assay

Caspase-3 activity was used as an index of apoptosis. RT4 and T24 cells were treated with acrolein $(100 \mu \mathrm{M})$, CAA $(10 \mu \mathrm{M})$, combination of acrolein and CAA, or vehicle for $24 \mathrm{~h}$. Caspase-3 activity was then determined using a caspase-3 fluorescence assay kit (Cat \#: 10009135, Cayman Chemicals, Ann Arbor, USA). Caspase-3 activity was normalized for cell density (resazurin data) and expressed as a fraction of untreated vehicle control.

\section{LDH Activity Assay}

The presence of LDH in samples from cultured urothelial cells was measured using a LDH Cytotoxicity Assay Kit as measure of membrane integrity. Cells were seeded and treated as described above and basal and hypotonic stretch samples were collected from each well and used for the LDH assay according to the manufacturers protocol.

\section{Statistical analysis}

Results were expressed as mean \pm standard error of the mean (SEM). Data were analysed using a Student t-test or one-way ANOVA with Dunnett or Tukey multiple comparisons test as appropriate, using Graphpad InStat3 software (SanDiego, CA). Significance levels were defined as $\mathrm{p}<0.05(*), \mathrm{p}<0.01(* *)$ and $\mathrm{p}<0.001(* * *)$.

\section{Materials}

Chemicals were of analytic grade and obtained from Sigma-Aldrich (St Louis, USA).

Cyclophosphamide (monohydrate salt), ifosfamide, acrolein, chloroacetaldehyde, resazurin salt, 2',7'-dichlorofluorescein diacetate (DCF-DA) and salts for Krebs-bicarbonate solution were purchased from Sigma-Aldrich (St Louis, USA). 


\section{Results}

Effects of cyclophosphamide, ifosfamide, acrolein and CAA on cell viability and ROS

\section{formation}

The toxicity of cyclophosphamide, ifosfamide, and the metabolites acrolein and CAA was first assessed in terms of ability to induce changes in urothelial cell viability and ROS formation. Twenty-four-hour exposure of either cell line to the parent compounds cyclophosphamide or ifosfamide at concentrations up to $100 \mu \mathrm{M}$ did not affect cell viability nor did either parent drug affect ROS formation (data not shown). However, both urinary metabolites, CAA and acrolein caused concentration dependent decreases in urothelial cell viability and increase in ROS production (Fig. 1).

On RT4 cells CAA was significantly more cytotoxic than acrolein and the mean $\mathrm{IC}_{50}$ value $[10(8-14) \mu \mathrm{M}]$ was significantly lower $(\mathrm{p}<0.01)$ than that for acrolein $[67(47-95) \mu \mathrm{M}]($ Fig 1 A). Similarly, on T24 cells, CAA was significantly $(\mathrm{p}<0.05)$ more toxic than acrolein with an $\mathrm{IC}_{50}$ of CAA $4(3-5) \mu \mathrm{M}$ compared with $15(12-14) \mu \mathrm{M}$ for acrolein (Fig 1-B). The cytotoxicity of CAA and acrolein was associated with increased ROS formation. At $10 \mu \mathrm{M}$ in RT4 cells ROS formation induced by CAA was significantly greater $(\mathrm{p}<0.001)$ than that induced by acrolein (Fig 1-C). In T24 cells, $1 \mu \mathrm{M}$ and $10 \mu \mathrm{M}$ CAA caused significantly greater $(\mathrm{p}<0.01)$ increases in ROS formation than acrolein at the same concentrations (Fig 1-D).

These metabolites are present in the urine together, so a combination of the two was also investigated. To determine whether the urinary concentration of acrolein (100nM) had an additive effect on the toxicity of CAA, a toxic CAA concentration was selected $(10 \mu \mathrm{M})$. The combination of the urinary acrolein concentrations of $100 \mathrm{nM}$ and $10 \mu \mathrm{M}$ CAA caused a significant reduction in cell viability in T24 cells similar to the effect seen after CAA alone (Fig 1C). However, in the RT4 cells, cell viability in the combination treated cells was 
significantly higher than after CAA $(10 \mu \mathrm{M})$ alone. ROS formation was also measured after treatment with the combination of acrolein $(100 \mathrm{nM})$ and CAA $(10 \mu \mathrm{M})$. Again, in T24 cells the increase in ROS production after treatment with the combination of metabolites was similar to that observed with CAA $(10 \mu \mathrm{M})$ alone, whereas in RT4 cells ROS formation was significantly lower in the combination treated cells than after CAA $(10 \mu \mathrm{M})$ alone (Fig 1F).

\section{Protective effects of $N$-acetyl cysteine (NAC)}

To determine if ROS formation played a causal role in CAA or acrolein induced cytotoxicity, cells were treated with the metabolites in the presence or absence of NAC. Acrolein $(100 \mu \mathrm{M})$ treatment caused basal ROS levels to increase to $305 \pm 8.9 \%$ of control levels in RT4 cells and to $1313 \pm 26.7 \%$ in $\mathrm{T} 24$ cells. NAC $(300 \mu \mathrm{M})$ prevented the increase in ROS production induced by acrolein in both cell lines, reducing ROS levels down to control levels in both cell lines $(\mathrm{p}<0.01)$ (Figure 2 A \& B). Similarly, CAA increased ROS production to $242 \pm 16.6 \%$ and $272 \pm 4.7 \%$ of control in RT4 and T24 cells respectively. Again, ROS production was restored to that of an untreated control by NAC $(300 \mu \mathrm{M})(103 \pm 5.8 \%$ of control in RT4 and $101 \pm 2.0 \%$ in T24 cells) $(\mathrm{p}<0.01)$ (Figure 2 C \& D). Similar protective effects were seen with $1 \mathrm{mM}$ NAC (Figure 2), and so all further experiments using NAC were performed at the lower concentration $(300 \mu \mathrm{M})$ only.

Acrolein $(100 \mu \mathrm{M})$ reduced cell survival to $37.2 \pm 2.4 \%$ in RT4 cells and $6.1 \pm 1.1 \%$ in T24 cells. The reduction in cell survival due to acrolein $(100 \mu \mathrm{M})$ was attenuated in the presence of NAC in both RT4 and T24 cells restoring cell viability to $83.7 \pm 5.2 \%$ and $84.9 \pm 6.6 \%$ of control respectively $(\mathrm{p}<0.01)$ (Figure 3A \& B). Similarly, CAA $(10 \mu \mathrm{M})$ reduced cell survival in RT4 cells to $62.0 \pm 2.8 \%$ of control and in T24 cells to $34.7 \pm 2 \%$. Again, cell survival was restored to that of an untreated control by NAC $(\mathrm{p}<0.01)$ (Figure $3 \mathrm{C} \& \mathrm{D})$. 
Twenty-four-hour exposure to acrolein, CAA or their combination was associated with a significant increase in caspase-3 activity in both cell line (Fig. 3E \& F), with the exception of $100 \mu \mathrm{M}$ acrolein in RT4 cells, where the increase was not statistically significant.

Co-treatment with NAC $(300 \mu \mathrm{M})$ again protected urothelial cells from CAA $(10 \mu \mathrm{M})$, reducing caspase-3 levels from $269 \pm 37 \%$ down to $83.4 \pm 8.8 \%$ of control in RT4 cells and from $355 \pm 48 \%$ to $179 \pm 37 \%$ of control in $\mathrm{T} 24$ cells $(\mathrm{p}<0.05)$ (Figure $3 \mathrm{E})$. The acrolein $(100 \mu \mathrm{M})$ induced increase in caspase-3 activity in T24 cells was also prevented by NAC with levels decreasing from $248 \pm 34 \%$ to $130 \pm 18 \%$ of control $(\mathrm{p}<0.05)$. NAC also protected urothelial cells from increased caspase- 3 activity due to the combination of acrolein $(100 \mu \mathrm{M})$ with CAA $(10 \mu \mathrm{M})$ reducing levels in both cell lines $(\mathrm{p}<0.05)$ (Figure 3F).

Effects of cyclophosphamide, ifosfamide, acrolein and CAA on cell mediator release Twenty-four-hour exposure of either cell line to $0.01-100 \mu \mathrm{M}$ cyclophosphamide or ifosfamide did not affect mediator release (data not shown). Also, at concentrations up to and including $10 \mu \mathrm{M}$, acrolein had no effect on ATP, ACh or PGE 2 levels in RT4 or T24 cells (Fig. 4 Data shown for $100 \mathrm{nM}$ acrolein). However, CAA $(10 \mu \mathrm{M})$ in T24 cells, caused a significant increase in basal and stimulated ATP levels (3.5-fold increase in basal samples and 5-fold increase in stimulated samples, $\mathrm{p}<0.001$ ) (Fig 4D). Basal levels of ACh were significantly reduced while stimulated levels were significantly increased after treatment with $10 \mu \mathrm{M}$ CAA $(50 \%$ decrease in basal levels $\mathrm{p}<0.05$ and 2.5-fold increase in stimulated levels $\mathrm{p}<0.01$ ) (Fig 4E). In both cell lines, basal $\mathrm{PGE}_{2}$ levels were increased significantly (approximately 2.5 -fold increase in both cell lines, $\mathrm{p}<0.05)$ after CAA treatment $(10 \mu \mathrm{M})($ Fig $4 \mathrm{C} \& \mathrm{~F})$. Treatment of RT4 or T24 urothelial cells with acrolein and CAA in binary combination resulted in the same level of ATP, $\mathrm{ACh}$ and $\mathrm{PGE}_{2}$ release as treatment with CAA alone (Fig 4). 
Acrolein had no effect on mediator release except at the highest concentration examined which is 1000 -fold greater than that appearing in the urine of patients. At this very high concentration $(100 \mu \mathrm{M})$, acrolein caused a 5-fold increase in basal ATP levels $(\mathrm{p}<0.001), 2.5$-fold increase in stimulated ATP levels $(\mathrm{p}<0.05)($ Fig 5A) and a 60\% increase in stimulated acetylcholine levels $(\mathrm{p}<0.001)$ in RT4 cells (Fig 5 B). PGE 2 levels in basal and stimulated samples from RT4 cells were also increased after treatment with this high concentration of acrolein (7.5- and 4-fold respectively, $\mathrm{p}<0.001$ ) (Fig 5C). No changes were observed in samples from T24 cells treated with $100 \mu \mathrm{M}$ acrolein as cell survival was too low.

Analysis of extracellular LDH activity revealed no change following exposure to acrolein or CAA and following the mediator sample collection procedure, confirming that levels of ATP, $\mathrm{ACh}$ and $\mathrm{PGE}_{2}$ measured in samples were released from cells and were not simply leaking from damaged cells.

Effects of $N$-acetyl cysteine on urothelial mediator release changes following acrolein or CAA treatment

Acrolien and CAA induced cell death and ROS production in human urothelial cells (Figure 1), with NAC offering protection against these changes (Figure 3) and so its protective effects on the functional changes to mediator release was considered next. Acrolein $(100 \mu \mathrm{M})$ treatment in RT4 cells caused a significant increase in both basal and stimulated ATP, PGE2 and ACh levels. These changes in mediator release could be prevented by co-treatment with NAC (Figure 5A-C) returning release of these mediators to levels comparable to untreated controls. In T24 cells CAA $(10 \mu \mathrm{M})$ treatment caused a significant increase in both basal and stimulated ATP and PGE2 levels. Basal levels of ACh were reduced while stimulated levels were increased after CAA treatment. Co-treatment with NAC again prevented these changes in mediator release (Figure 5D-F). 


\section{Discussion and Conclusions}

Cyclophosphamide and ifosfamide treatment are associated with bladder toxicity. The urothelium has been shown to be able to communicate with the detrusor, myofibroblasts and sensory nerves by releasing ATP, ACh and $\mathrm{PGE}_{2}$ among other mediators (Sellers et al. 2018). Changes in these transmitters have been linked to bladder function diseases and sensory changes. This study is the first to focus on the effects of CAA on urothelial viability and functional mediator release, and compared to the effects of acrolein, the metabolite typically linked to bladder toxicity of cyclophosphamide and ifosfamide.

In this study, urothelial cell viability was reduced by acrolein and by CAA confirming that both metabolites are toxic to the urothelium. However, chloroacetaldehyde was more toxic to urothelial cells than acrolein, with a 7- and 4-fold greater cytotoxic potency in RT4 and T24 cells respectively, based in $\mathrm{IC}_{50}$ values. The reduction in cell viability after treatment with acrolein was accompanied by an increase in ROS production which is in line with previous studies. CAA treatment at $10 \mu \mathrm{M}$ in both cell lines produced significant changes in both cell viability and ROS production but at $1 \mu \mathrm{M}$ ROS production did not change despite cell viability being significantly reduced. This suggests that CAA toxicity at higher concentrations may involve ROS, similar to acrolein toxicity, while at lower concentrations it may induce an alternative cell death pathway. A study by MacAllister et al. (2012) showed that depletion of the endogenous antioxidant GSH increased the toxicity of acrolein but not CAA in rat hepatocytes suggesting that CAA may cause cell death via a pathway other than ROS production. This study has shown that CAA significantly affected urothelial cell viability and ROS formation at lower concentrations than that of acrolein suggesting that chloroacetaldehyde may also contribute to the urotoxicity of cyclophosphamide and ifosfamide, not just acrolein as previously thought. Nephrotoxicity is observed in patients following ifosfamide but not 
cyclophosphamide treatment, and it is believed that CAA is responsible for renal toxicity as it is the main product of ifosfamide metabolism. Recent studies assessing the nephrotoxicity of CAA suggest that concentrations of $25-75 \mu \mathrm{M}$ are clinically relevant (Benesic et al. 2014). Here we observed urothelial toxicity and altered urothelial function following exposure to concentrations of CAA below this range, with $\mathrm{IC}_{50}$ values of $10(8-14) \mu \mathrm{M}$ and 4 (3-5) $\mu \mathrm{M}$, in RT4 and T24 cells respectively highlighting the relevance to clinically levels.

Acrolein and CAA would be present in the urine together and this is the first study to consider the combined effect of the two toxic metabolites. Surprisingly, combining the likely urinary concentration of acrolein $(100 \mathrm{nM})$ with a toxic concentration of CAA $(10 \mu \mathrm{M})$ was not more toxic than CAA treatment alone. Rather, acrolein $(100 \mathrm{nM})$ appeared to have a slight protective effect against cell death and ROS formation when combined with CAA $(10 \mu \mathrm{M})$. At lower concentrations, acrolein can affect transcription factors such as nuclear factor-kappa B (NFкB) (Horton et al. 1999) and activator protein-1 (AP-1) (Biswal et al. 2002; Korkmaz et al. 2007). Both of these transcription factors can have anti- or pro-apoptotic effects. It is possible that $100 \mathrm{nM}$ acrolein, by way of transcription factors, may be having protective, anti-apoptotic effects and protecting the cells from CAA induced death. This is consistent with our reported findings in the T24 cell line, where caspase-3 activity was equivalent in the acrolein and combination groups.

The function of the urothelial cells that remain after treatment with cyclophosphamide and ifosfamide was also of interest in this study. It is now well established that ATP plays a major role in bladder sensory mechanotransduction mechanisms. There is basal release of ATP from urothelial cells (Kang et al. 2013a) and additional ATP release can be stimulated in response to stretch during bladder filling (Kang et al. 2013a; Sadananda et al. 2009). Urothelial ATP 
acts on $\mathrm{P} 2 \mathrm{X} 3$ and possibly $\mathrm{P} 2 \mathrm{X} 2$ receptors on sensory nerves to transmit the sensation of bladder filling to the CNS (Burnstock 2009). ATP can have effects on both low and high threshold nerve fibres, altering the micturition reflex and pain sensations respectively (Burnstock 2009; Rong et al. 2002). In our study acrolein and CAA increased both basal and stimulated ATP release from urothelial cells. However, CAA was more toxic than acrolein, inducing the changes in ATP at a 10 -fold lower concentration $(10 \mu \mathrm{M})$. It is possible that higher basal ATP levels in patients treated with cyclophosphamide or ifosfamide may be responsible for the urinary frequency and feelings of residual volume experienced by patients. An increase in stretch induced ATP levels after cyclophosphamide or ifosfamide treatment may also contribute to more frequent urges to urinate and could be responsible for the reported painful sensations as the bladder fills or on voiding.

It has also been reported that ATP increases the excitability of afferent nerves (Burnstock 2011) and enhances its own release from urothelial cells (Birder 2010), while cyclophosphamide treatment enhances and sensitises P2X receptor activity (Dang et al. 2008). Studies of a comparable disease in cats (i.e. feline interstitial cystitis) has demonstrated increased stretchevoked release of ATP from the urothelium as well as changes in purinergic receptor profiles in urothelial cells (Birder et al. 2003). Therefore, the combined effect of more ATP and more sensitive purinergic receptors on afferent nerves is a likely explanation of the sensory changes seen after cyclophosphamide and ifosfamide treatment. Both acrolein and CAA treatment resulted in an increase in ATP release from human urothelial cells and accordingly is likely to contribute to the urotoxicity of cyclophosphamide and ifosfamide. However, CAA caused an increase in ATP at a lower concentration than acrolein potentially making CAA the more urotoxic metabolite. 
The urothelium has also been shown to release ACh in response to stretch and is thought to act on muscarinic receptors on the urothelium and on the sensory nerves (Yoshida et al. 2006). The activation of urothelial muscarinic receptors leads to release of several substances including ATP and $\mathrm{PGE}_{2}$ as well as the urothelium derived inhibitory factor (UDIF) (HannaMitchell and Birder 2008; Hawthorn et al. 2000; Yokoyama et al. 2011). The effect of ACh on afferent nerves in the bladder is still unclear with both inhibitory and stimulatory effects reported (Daly et al. 2010; Iijima et al. 2007).

Acrolein and CAA treatment both caused increased stretch-induced levels of ACh, however CAA was again the more potent metabolite inducing this change at a concentration $(10 \mu \mathrm{M}) 10$ fold lower than acrolein $(100 \mu \mathrm{M})$. The increased ACh during stretch may be acting directly on the detrusor muscle or the afferent nerves to affect functional and sensory changes in the bladder. However, it is also possible that the change in ACh levels alters the release of other transmitters from the urothelium, indirectly contributing to the bladder changes after cyclophosphamide or ifosfamide treatment. Specifically, more ACh may act in an autocrine manner causing greater ATP release which in turn could lead to sensory changes in patients.

The urothelium expresses cyclooxygenase (COX)-1 and COX-2 enzymes which are responsible for the synthesis of prostanoids including prostaglandin $E_{2}$ (de Jongh et al. 2009). Several studies in rats and mice have found that systemic treatment with cyclophosphamide, ifosfamide or intravesicular treatment with acrolein induces COX-2 expression in urothelium within 12-24 hours of treatment (Klinger et al. 2007; Macedo et al. 2008; Macedo et al. 2011) and one study found that the plasma $\mathrm{PGE}_{2}$ concentration was increased after administration of ifosfamide (Macedo et al. 2011). However, the present study is the first to investigate the effect of acrolein and CAA on the release of $\mathrm{PGE}_{2}$ from urothelial cells. Acrolein treatment $(100 \mu \mathrm{M})$ 
caused an increase in basal and stimulated $\mathrm{PGE}_{2}$ release from the urothelial cells. CAA treatment $(10 \mu \mathrm{M})$ also caused significantly more basal $\mathrm{PGE}_{2}$ to be released from urothelial cells and while stimulated release was increased it was not significant. $\mathrm{PGE}_{2}$ released from the urothelium is thought to activate or sensitize afferent nerves (de Groat and Yoshimura 2001) and cause stimulation of the detrusor muscle increasing resting tone and spontaneous contractions (de Jongh et al. 2007). In addition, $\mathrm{PGE}_{2}$, released from afferent nerves or the urothelial cells and acting via EP1 and/or EP3 receptors on urothelial cells stimulates the release of ATP (Tanaka et al. 2011). Both metabolites caused higher basal $\mathrm{PGE}_{2}$ levels which may lead to sensitisation of afferent nerves and as a result altered micturition reflex, hyperactivity and feelings of residual volume. Furthermore, increased stimulated $\mathrm{PGE}_{2}$ release may contribute to the feelings of pain during filling or voiding experienced by patients treated with cyclophosphamide or ifosfamide. Again, CAA appeared to be more potent inducing changes in $\mathrm{PGE}_{2}$ at a concentration $(10 \mu \mathrm{M}) 10$-fold lower than acrolein $(100 \mathrm{nM})$.

Inthis study, NAC protected the urothelial cells from acrolein and CAA induced cell death and ROS formation restoring cell survival and ROS levels to that of an untreated control. Furthermore, NAC prevented the functional changes to acrolein or CAA in the cells, with levels of all mediators being the same as untreated controls. These are promising results as it appears NAC can fully protect urothelial cells from acrolein or CAA damage. Few studies have looked at the ability of NAC to protect urothelial cells from cyclophosphamide or ifosfamide induced toxicity. In exfoliated bladder cells from mice treated with cyclophosphamide, with and without oral NAC supplementation, it was shown that genotoxicity, inflammatory infiltration and haemorrhage were prevented by NAC (Gurbuz et al. 2009). However, NAC has shown similar protective effects against hepatotoxicity and nephrotoxicity (Chen et al. 2007; Chen et al. 2008; Hanly et al. 2012; Macallister et al. 2012; Mohammad et al. 2012). 
Tanel and Averill-Bates (2007) demonstrated that the mechanism by which NAC protected chinese hamster ovary cells from acrolein cytotoxicity was by increasing intracellular GSH and preventing apoptosis. Furthermore, NAC has been shown to stop ROS induced apoptosis in human bladder urothelial cells due to sulforaphane and compound K (Jo et al. 2014). As described in the results above, NAC was able to prevent the increase in caspase- 3 activity due to acrolein and CAA treatment of human urothelial cells supporting an anti-apototic mechanism of action. However, NAC also reduced ROS production in both cells lines which suggests that the mechanism of NAC protection may be the prevention of oxidative stress. From these results, NAC appears to be a promising alternative or addition to current uroprotective co-treatments for cyclophosphamide and ifosfamide therapy. NAC not only appears to protect urothelial cells from damage but also from the functional changes induced by acrolein and CAA.

NAC given orally is excreted in the urine in the form of both NAC and cysteine (Ventura et al. 2003) making it possible that a simple oral dose of NAC could protect patients from acrolein and CAA induced urotoxicity. For patients this could mean oral supplementation during and after treatment with cyclophosphamide or ifosfamide could reduce the pain, urinary frequency and urgency associated with these drugs and potentially improve treatment tolerability and outcomes.

In summary, our study has demonstrated that both acrolein and CAA are toxic to the urothelium causing increased ROS production and decreasing cell viability. Furthermore, both metabolites cause changes in urothelial mediator levels which could contribute to the sensory and functional changes experienced by patients after treatment with cyclophosphamide or 
ifosfamide. Specifically, increased ATP and $\mathrm{PGE}_{2}$ levels may cause sensitised afferent nerves leading to an altered micturition reflex, hyperactivity, feelings of residual volume and pain sensations. CAA was shown to be more toxic to cultured human urothelial cells than acrolein, inducing significant changes at clinically relevant concentrations. This study has shown that NAC appears to protect urothelial cells from the acrolein and CAA induced changes and accordingly may be useful in preventing urotoxicity in patients receiving cyclophosphamide and ifosfamide chemotherapy.

\section{Conflict of Interest Statement:}

The authors declare that they have no conflict of interest. 


\section{References}

Al-Rawithi S, El-Yazigi A, Ernst P, Al-Fiar F, Nicholls PJ (1998) Urinary excretion and pharmacokinetics of acrolein and its parent drug cyclophosphamide in bone marrow transplant patients. Bone Marrow Transplant 22(5):485-90 doi:10.1038/sj.bmt.1701355

Anoopkumar-Dukie S, Carey JB, Conere T, O'Sullivan E, van Pelt FN, Allshire A (2005) Resazurin assay of radiation response in cultured cells. British Journal of Radiology 78(934):945-7 doi:10.1259/bjr/54004230

Aronsson P, Johnsson M, Vesela R, Winder M, Tobin G (2012) Adenosine receptor antagonism suppresses functional and histological inflammatory changes in the rat urinary bladder. Autonomic neuroscience : basic \& clinical 171(1-2):49-57 doi:10.1016/j.autneu.2012.10.006

Beauchamp RO, Jr., Andjelkovich DA, Kligerman AD, Morgan KT, Heck HD (1985) A critical review of the literature on acrolein toxicity. Crit Rev Toxicol 14(4):309-80 doi:10.3109/10408448509037461

Benesic A, Schwerdt G, Hennemeier I, Sauvant C, Mildenberger S, Gekle M (2014) The nephrotoxic Ifosfamide-metabolite chloroacetaldehyde interferes with renal extracellular matrix homeostasis. Cell Physiol Biochem 33(4):1106-16 doi:10.1159/000358680

Birder L, Andersson KE (2013) Urothelial signaling. Physiol Rev 93(2):653-80 doi:10.1152/physrev.00030.2012

Birder LA (2010) Urothelial signaling. Autonomic neuroscience : basic \& clinical 153(12):33-40 doi:10.1016/j.autneu.2009.07.005

Birder LA, Barrick SR, Roppolo JR, et al. (2003) Feline interstitial cystitis results in mechanical hypersensitivity and altered ATP release from bladder urothelium. American journal of physiology Renal physiology 285(3):F423-9 doi:10.1152/ajprenal.00056.2003

Birder LA, Kanai AJ, Cruz F, Moore K, Fry CH (2010) Is the urothelium intelligent? Neurourol Urodyn 29(4):598-602 doi:10.1002/nau.20914

Biswal S, Acquaah-Mensah G, Datta K, Wu X, Kehrer JP (2002) Inhibition of cell proliferation and AP-1 activity by acrolein in human A549 lung adenocarcinoma cells due to thiol imbalance and covalent modifications. Chem Res Toxicol 15(2):180-6

Brock N, Stekar J, Pohl J, Niemeyer U, Scheffler G (1979) Acrolein, the causative factor of urotoxic side-effects of cyclophosphamide, ifosfamide, trofosfamide and sufosfamide. Arzneimittelforschung 29(4):659-61

Burnstock G (2009) Purinergic mechanosensory transduction and visceral pain. Mol Pain 5:69 doi:10.1186/1744-8069-5-69

Burnstock G (2011) Therapeutic potential of purinergic signalling for diseases of the urinary tract. BJU Int 107(2):192-204 doi:10.1111/j.1464-410X.2010.09926.X

Chen N, Aleksa K, Woodland C, Rieder M, Koren G (2007) The effect of N-acetylcysteine on ifosfamide-induced nephrotoxicity: in vitro studies in renal tubular cells. Transl Res 150(1):51-7 doi:10.1016/j.trsl.2007.02.001

Chen N, Aleksa K, Woodland C, Rieder M, Koren G (2008) N-Acetylcysteine prevents ifosfamide-induced nephrotoxicity in rats. Br J Pharmacol 153(7):1364-72 doi:10.1038/bjp.2008.15

Coggins PR, Ravdin RG, Eisman SH (1960) Clinical evaluation of a new alkylating agent: cytoxan (cyclophosphamide). Cancer 13:1254-60 
Daly DM, Chess-Williams R, Chapple C, Grundy D (2010) The inhibitory role of acetylcholine and muscarinic receptors in bladder afferent activity. Eur Urol 58(1):228; discussion 31-2 doi:10.1016/j.eururo.2009.12.030

Dang K, Lamb K, Cohen M, Bielefeldt K, Gebhart GF (2008) Cyclophosphamide-induced bladder inflammation sensitizes and enhances $\mathrm{P} 2 \mathrm{X}$ receptor function in rat bladder sensory neurons. J Neurophysiol 99(1):49-59 doi:10.1152/jn.00211.2007

de Groat WC, Yoshimura N (2001) Pharmacology of the lower urinary tract. Annu Rev Pharmacol Toxicol 41:691-721 doi:10.1146/annurev.pharmtox.41.1.691

de Jongh R, Grol S, van Koeveringe GA, van Kerrebroeck PE, de Vente J, Gillespie JI (2009) The localization of cyclo-oxygenase immuno-reactivity (COX I-IR) to the urothelium and to interstitial cells in the bladder wall. J Cell Mol Med 13(9B):3069-81 doi:10.1111/j.1582-4934.2008.00475.x

de Jongh R, van Koeveringe GA, van Kerrebroeck PE, Markerink-van Ittersum M, de Vente J, Gillespie JI (2007) The effects of exogenous prostaglandins and the identification of constitutive cyclooxygenase I and II immunoreactivity in the normal guinea pig bladder. BJU Int 100(2):419-29 doi:10.1111/j.1464-410X.2007.07011.x

Deberry JJ, Schwartz ES, Davis BM (2014) TRPA1 mediates bladder hyperalgesia in a mouse model of cystitis. Pain doi:10.1016/j.pain.2014.03.023

Fukuoka M, Negoro S, Masuda N, et al. (1991) Placebo-controlled double-blind comparative study on the preventive efficacy of mesna against ifosfamide-induced urinary disorders. J Cancer Res Clin Oncol 117(5):473-8

Golubeva AV, Zhdanov AV, Mallel G, Dinan TG, Cryan JF (2014) The mouse cyclophosphamide model of bladder pain syndrome: tissue characterization, immune profiling, and relationship to metabotropic glutamate receptors. Physiol Rep 2(3):e00260 doi:10.1002/phy2.260

Goren MP, Wright RK, Pratt CB, Pell FE (1986) Dechloroethylation of ifosfamide and neurotoxicity. Lancet 2(8517):1219-20

Gurbuz N, Ozkul A, Burgaz S (2009) Effects of vitamin C and N-acetylcysteine against cyclophosphamide-induced genotoxicity in exfoliated bladder cells of mice in vivo. $\mathrm{J}$ BUON 14(4):647-52

Hanly L, Figueredo R, Rieder MJ, Koropatnick J, Koren G (2012) The Effects of Nacetylcysteine on ifosfamide efficacy in a mouse xenograft model. Anticancer Res 32(9):3791-8

Hanna-Mitchell AT, Birder LA (2008) New insights into the pharmacology of the bladder. Curr Opin Urol 18(4):347-52 doi:10.1097/MOU.0b013e3283023bfc

Hawthorn MH, Chapple CR, Cock M, Chess-Williams R (2000) Urothelium-derived inhibitory factor(s) influences on detrusor muscle contractility in vitro. British journal of pharmacology 129(3):416-9 doi:10.1038/sj.bjp.0703068

Horton ND, Biswal SS, Corrigan LL, Bratta J, Kehrer JP (1999) Acrolein causes inhibitor kappaB-independent decreases in nuclear factor kappaB activation in human lung adenocarcinoma (A549) cells. J Biol Chem 274(14):9200-6

Iijima K, De Wachter S, Wyndaele JJ (2007) Effects of the M3 receptor selective muscarinic antagonist darifenacin on bladder afferent activity of the rat pelvic nerve. Eur Urol 52(3):842-7 doi:10.1016/j.eururo.2007.02.057

Jo GH, Kim GY, Kim WJ, Park KY, Choi YH (2014) Sulforaphane induces apoptosis in T24 human urinary bladder cancer cells through a reactive oxygen species-mediated mitochondrial pathway: the involvement of endoplasmic reticulum stress and the Nrf2 signaling pathway. Int J Oncol 45(4):1497-506 doi:10.3892/ijo.2014.2536

Joqueviel C, Malet-Martino M, Martino R (1997) A 13C NMR study of 2-(13)Cchloroacetaldehyde, a metabolite of ifosfamide and cyclophosphamide, in the isolated 
perfused rabbit heart model. Initial observations on its cardiotoxicity and cardiac metabolism. Cell Mol Biol (Noisy-le-grand) 43(5):773-82

Kang SH, Chess-Williams R, Anoopkumar-Dukie S, McDermott C (2013a) Induction of inflammatory cytokines and alteration of urothelial ATP, acetylcholine and prostaglandin E2 release by doxorubicin. Eur J Pharmacol 700(1-3):102-9 doi:10.1016/j.ejphar.2012.11.053

Kang SH, Chess-Williams R, Anoopkumar-Dukie S, McDermott C (2013b) Induction of inflammatory cytokines and alteration of urothelial ATP, acetylcholine and prostaglandin E2 release by doxorubicin. Eur J Pharmacol 700(1-3):102-9 doi:10.1016/j.ejphar.2012.11.053

Kehrer JP, Biswal SS (2000) The molecular effects of acrolein. Toxicol Sci 57(1):6-15

Klinger MB, Dattilio A, Vizzard MA (2007) Expression of cyclooxygenase-2 in urinary bladder in rats with cyclophosphamide-induced cystitis. American journal of physiology Regulatory, integrative and comparative physiology 293(2):R677-85 doi:10.1152/ajpregu.00305.2007

Korkmaz A, Topal T, Oter S (2007) Pathophysiological aspects of cyclophosphamide and ifosfamide induced hemorrhagic cystitis; implication of reactive oxygen and nitrogen species as well as PARP activation. Cell Biol Toxicol 23(5):303-12 doi:10.1007/s10565-006-0078-0

Kumar V, Chapple CR, Rosario D, Tophill PR, Chess-Williams R (2010) In vitro release of adenosine triphosphate from the urothelium of human bladders with detrusor overactivity, both neurogenic and idiopathic. Eur Urol 57(6):1087-92 doi:10.1016/j.eururo.2009.11.042

Kumar V, Chapple CR, Surprenant AM, Chess-Williams R (2007) Enhanced adenosine triphosphate release from the urothelium of patients with painful bladder syndrome: a possible pathophysiological explanation. J Urol 178(4 Pt 1):1533-6 doi:10.1016/j.juro.2007.05.116

Lawson M, Vasilaras A, De Vries A, Mactaggart P, Nicol D (2008) Urological implications of cyclophosphamide and ifosfamide. Scand J Urol Nephrol 42(4):309-17 doi:10.1080/00365590701570953

Macallister SL, Martin-Brisac N, Lau V, Yang K, O'Brien PJ (2012) Acrolein and chloroacetaldehyde: An examination of the cell and cell-free biomarkers of toxicity. Chemico-Biological Interactions doi:10.1016/j.cbi.2012.11.017

Macedo FY, Baltazar F, Mourao LC, et al. (2008) Induction of COX-2 expression by acrolein in the rat model of hemorrhagic cystitis. Exp Toxicol Pathol 59(6):425-30 doi:10.1016/j.etp.2007.10.010

Macedo FY, Mourao LT, Palheta RC, Jr., et al. (2011) Cyclooxygenase-2 contributes to functional changes seen on experimental hemorrhagic cystitis induced by ifosfamide in rat urinary bladder. Cancer Chemother Pharmacol 67(4):935-43 doi:10.1007/s00280-010-1392-z

Mansfield KJ, Hughes JR (2014) Effect of inflammatory mediators on ATP release of human urothelial RT4 cells. Biomed Res Int 2014:182862 doi:10.1155/2014/182862

McDermott C, Chess-Williams R, Grant GD, et al. (2012) Effects of Pseudomonas aeruginosa virulence factor pyocyanin on human urothelial cell function and viability. J Urol 187(3):1087-93 doi:10.1016/j.juro.2011.10.129

Mohammad MK, Avila D, Zhang J, et al. (2012) Acrolein cytotoxicity in hepatocytes involves endoplasmic reticulum stress, mitochondrial dysfunction and oxidative stress. Toxicol Appl Pharmacol 265(1):73-82 doi:10.1016/j.taap.2012.09.021 
Nissim I, Horyn O, Daikhin Y, Luhovyy B, Phillips PC, Yudkoff M (2006) Ifosfamideinduced nephrotoxicity: mechanism and prevention. Cancer Res 66(15):7824-31 doi:10.1158/0008-5472.CAN-06-1043

Pendyala L, Creaven PJ, Schwartz G, et al. (2000) Intravenous ifosfamide/mesna is associated with depletion of plasma thiols without depletion of leukocyte glutathione. Clin Cancer Res 6(4):1314-21

Rong W, Spyer KM, Burnstock G (2002) Activation and sensitisation of low and high threshold afferent fibres mediated by $\mathrm{P} 2 \mathrm{X}$ receptors in the mouse urinary bladder. $\mathrm{J}$ Physiol 541(Pt 2):591-600

Sadananda P, Shang F, Liu L, Mansfield KJ, Burcher E (2009) Release of ATP from rat urinary bladder mucosa: role of acid, vanilloids and stretch. British journal of pharmacology 158(7):1655-62 doi:10.1111/j.1476-5381.2009.00431.x

Schwerdt G, Gordjani N, Benesic A, et al. (2006) Chloroacetaldehyde- and acrolein-induced death of human proximal tubule cells. Pediatr Nephrol 21(1):60-7 doi:10.1007/s00467-005-2006-6

Sellers D, Chess-Williams R, Michel MC (2018) Modulation of lower urinary tract smooth muscle contraction and relaxation by the urothelium. Naunyn Schmiedebergs Arch Pharmacol 391(7):675-694 doi:10.1007/s00210-018-1510-8

Sladek NE (1988) Metabolism of oxazaphosphorines. Pharmacol Ther 37(3):301-55

Sood C, O'Brien PJ (1993) Molecular mechanisms of chloroacetaldehyde-induced cytotoxicity in isolated rat hepatocytes. Biochem Pharmacol 46(9):1621-6

Takamoto S, Sakura N, Namera A, Yashiki M (2004) Monitoring of urinary acrolein concentration in patients receiving cyclophosphamide and ifosphamide. J Chromatogr B Analyt Technol Biomed Life Sci 806(1):59-63 doi:10.1016/j.jchromb.2004.02.008

Tanaka I, Nagase K, Tanase K, Aoki Y, Akino H, Yokoyama O (2011) Modulation of stretch evoked adenosine triphosphate release from bladder epithelium by prostaglandin E. J Urol 185(1):341-6 doi:10.1016/j.juro.2010.09.042

Tanel A, Averill-Bates DA (2007) Inhibition of acrolein-induced apoptosis by the antioxidant N-acetylcysteine. J Pharmacol Exp Ther 321(1):73-83 doi:10.1124/jpet.106.114678

Ventura P, Panini R, Abbati G, Marchetti G, Salvioli G (2003) Urinary and plasma homocysteine and cysteine levels during prolonged oral $\mathrm{N}$-acetylcysteine therapy. Pharmacology 68(2):105-14 doi:10.1159/000069535

Yokoyama O, Tanaka I, Kusukawa N, et al. (2011) Antimuscarinics suppress adenosine triphosphate and prostaglandin E2 release from urothelium with potential improvement in detrusor overactivity in rats with cerebral infarction. J Urol 185(6):2392-7 doi:10.1016/j.juro.2011.02.048

Yoshida M, Inadome A, Maeda Y, et al. (2006) Non-neuronal cholinergic system in human bladder urothelium. Urology 67(2):425-30 doi:10.1016/j.urology.2005.08.014 

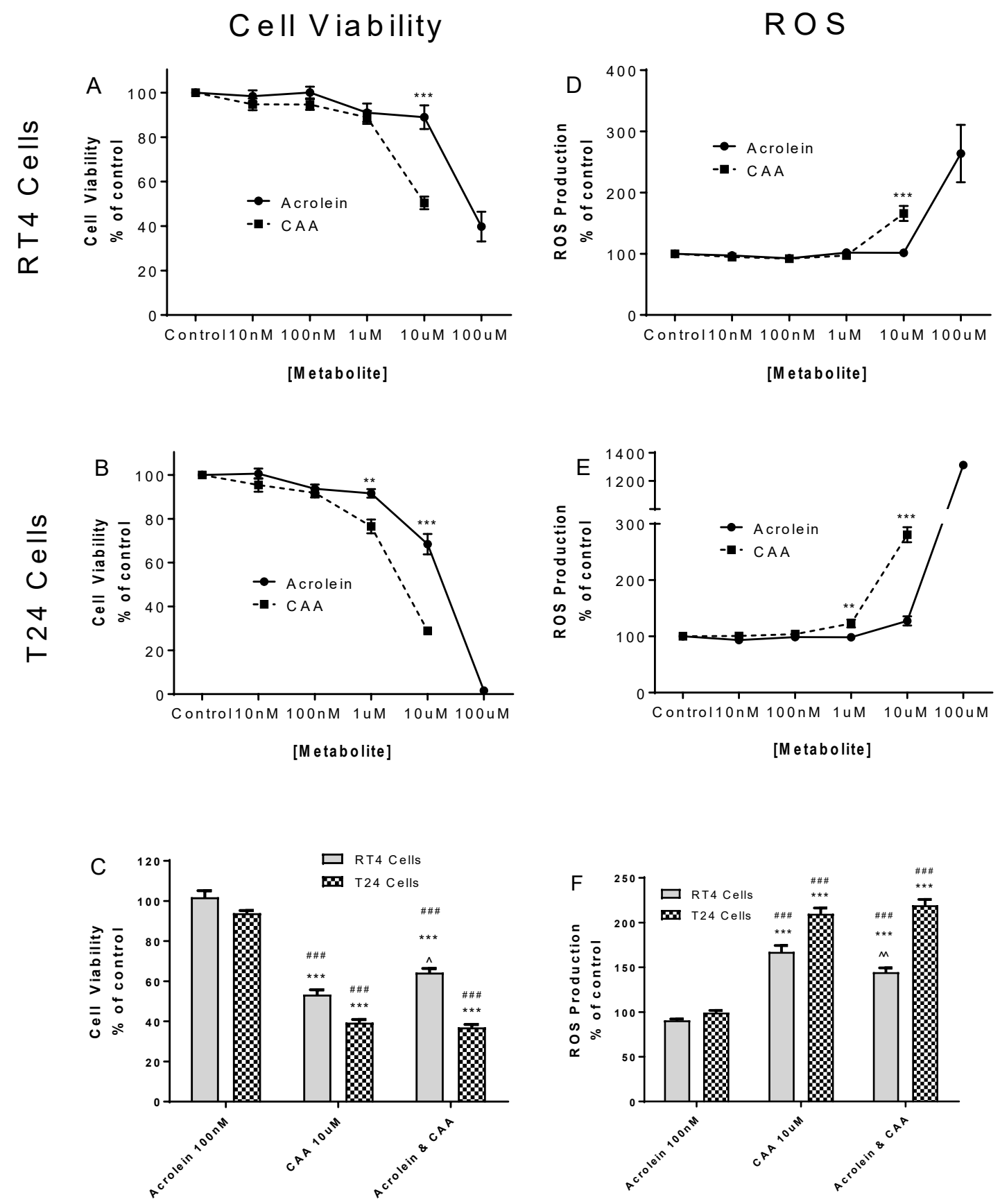

Fig. 1 Effect of 24 hour acrolein, chloroacetaldehyde (CAA) or combination treatment on cell viability and ROS production in RT4 (A, C, D \& F) and T24 (B, C, E \& F) human urothelial cells. Data are shown as a percentage of control ( $m e a n \pm S E M, n=6)$ and analysed by unpaired two-tailed t-test for A-D $(* * p<0.01, * * * p<0.001 v s$ CAA) or analysed by 1 -way ANOVA with Tukey posttest for $\mathrm{E} \& \mathrm{~F}$ (\#\#\# $\mathrm{p}<0.001 \mathrm{vs}$ control, ${ }^{* * *} \mathrm{p}<0.001 \mathrm{vs}$ acrolein $(100 \mathrm{nM}),{ }^{\wedge} \mathrm{p}<0.05$ $\&^{\wedge}{ }^{\wedge} \mathrm{p}<0.01$ vs CAA (10uM)). Note: Y Axis split on graph $\mathrm{E}$ 
A

RT 4 Cells

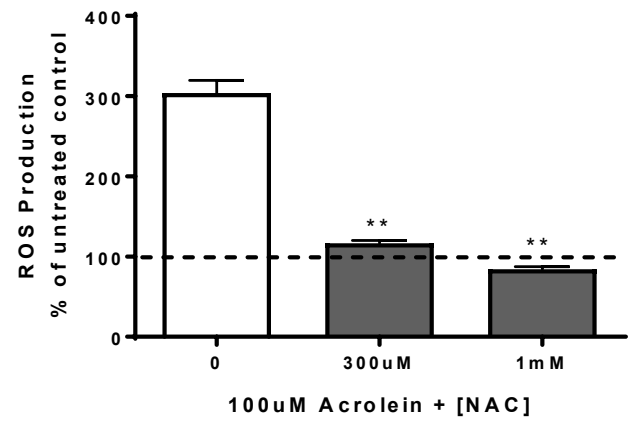

C

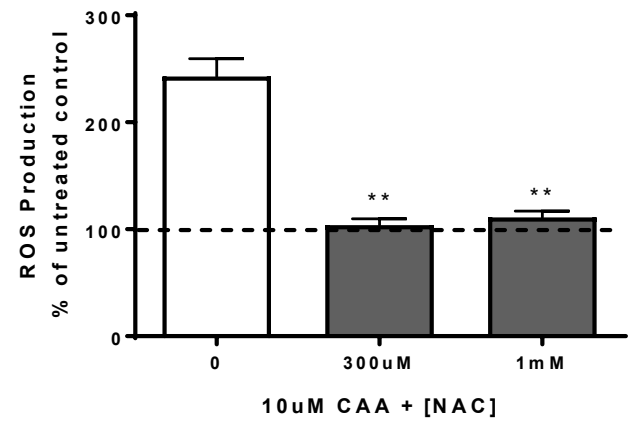

T24 Cells

B

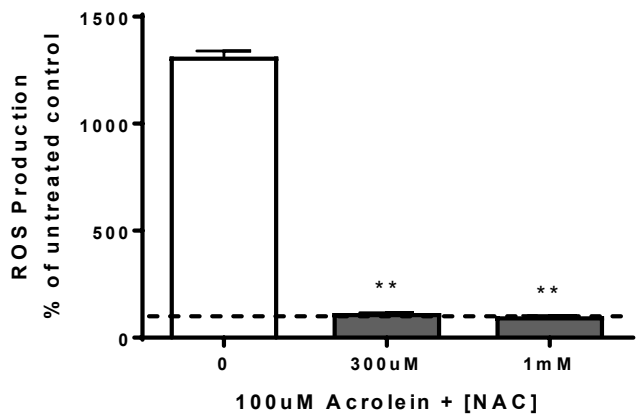

D

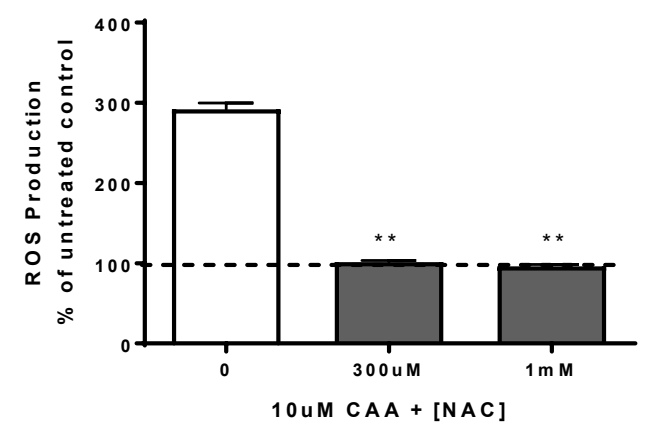

Fig. 2 Effect of NAC on ROS production in RT4 (A \& C) and T24 (B \& D) following acrolein or CAA treatment. Data presented as mean $\pm \operatorname{SEM}(n=6)$ and analysed by 1 -way ANOVA with Dunnett's posttest $(* * p<0.01$ vs control CAA or Acrolein in the absence of NAC) 

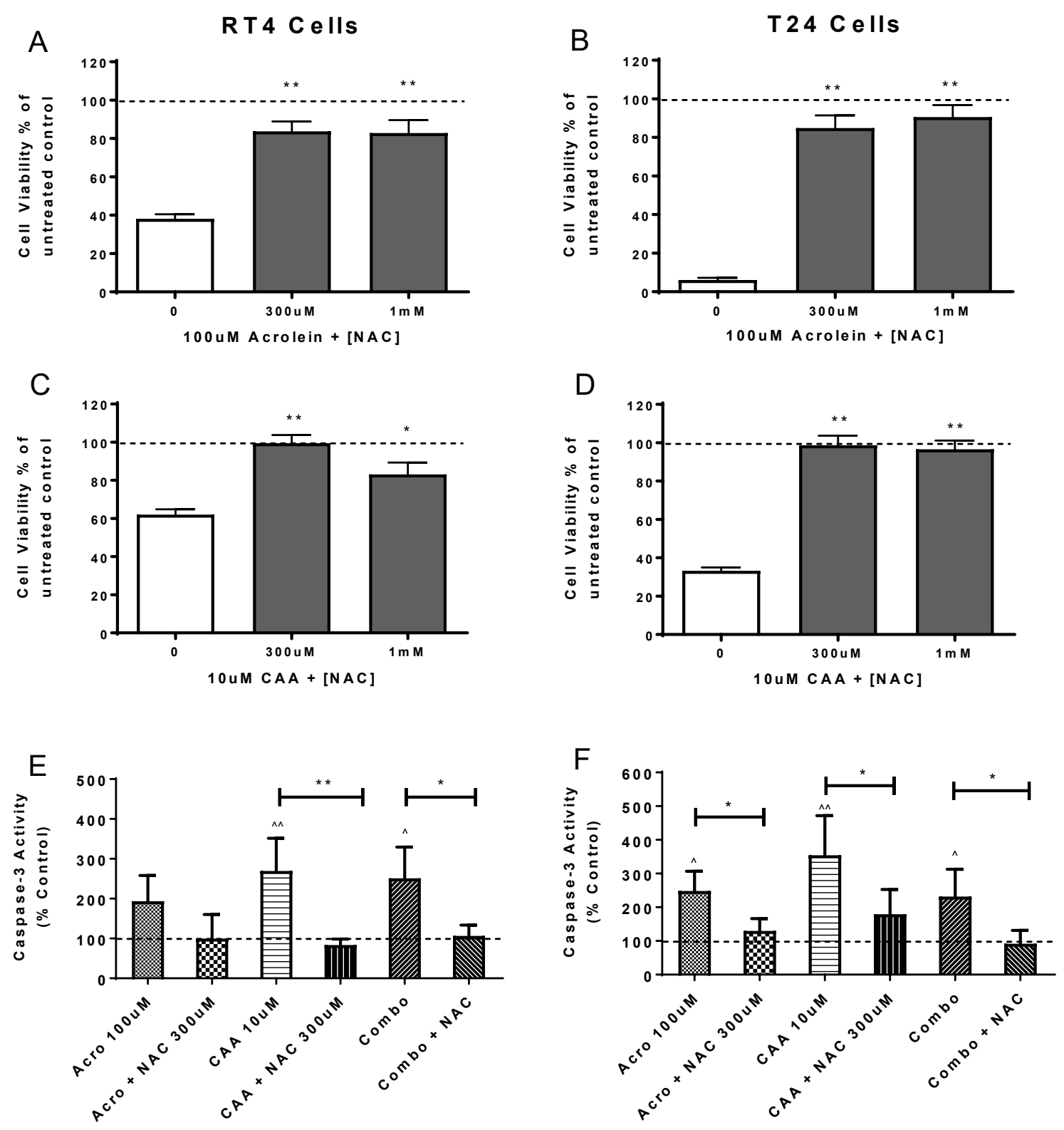

Fig. 3 Effect of NAC on changes in cell viability and caspase-3 activity caused by 24-hour exposure to acrolein or CAA. Data are shown as a percentage of untreated control (mean \pm SEM, $n=6$ ) and analysed using 1-way ANOVA with Dunnett's posttest (A-D *vs Control Acrolein or CAA in absence of NAC) or Tukey-Kramer posttest (E-F* with vs without NAC, $\wedge$ vs untreated control) 

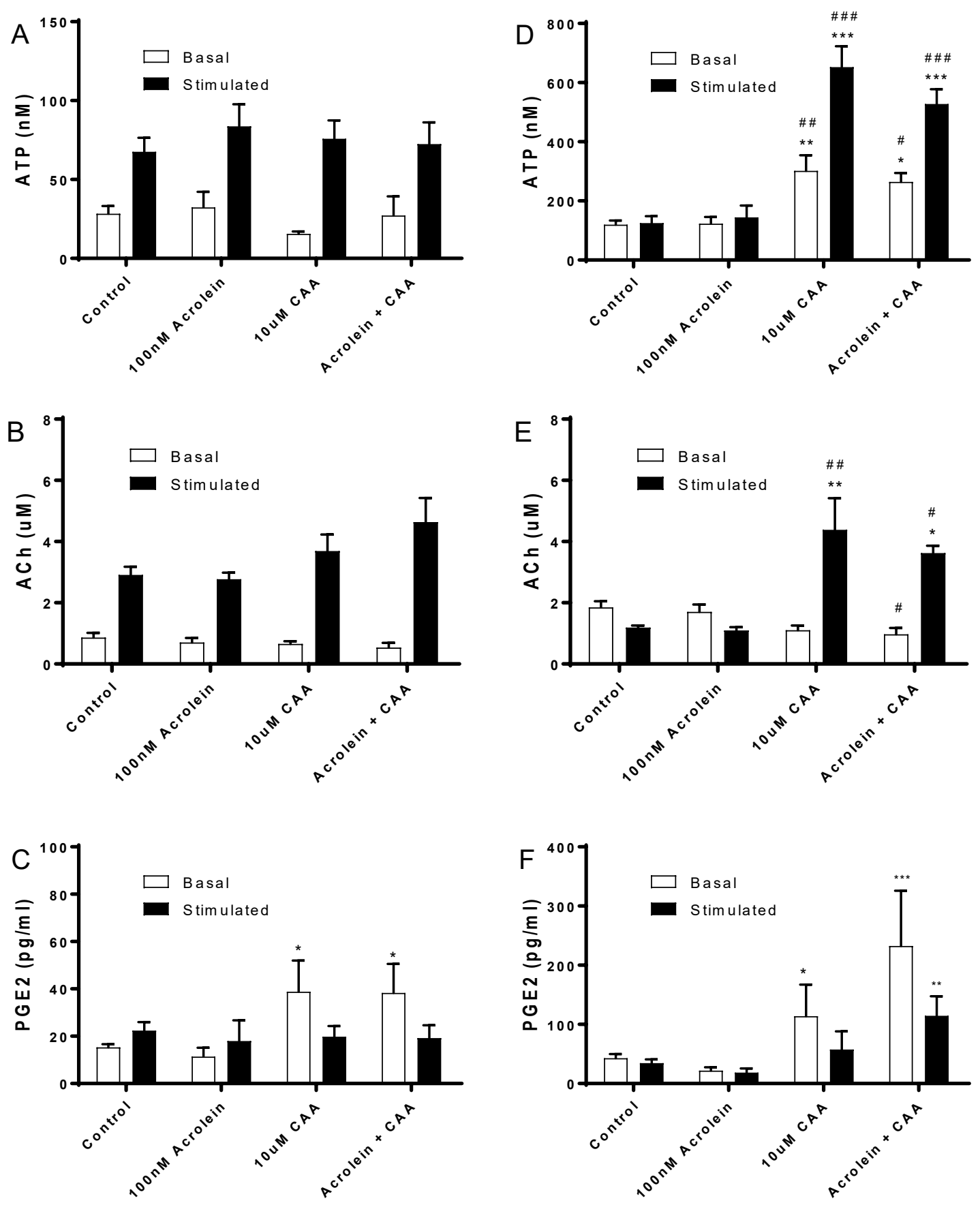

Fig. 4 Effect of 24 hour acrolein $(100 \mathrm{nM})$, chloroacetaldehyde (CAA) $(10 \mu \mathrm{M})$ or acrolein $(100 \mathrm{nM})$ combined with CAA $(10 \mu \mathrm{M})$ treatment on basal and hypo-osmotically stimulated ATP, ACh and $\mathrm{PGE}_{2}$ levels in RT4 (A, B \& C respectively) and T24 cells (D, E \& F respectively). Data are shown as mean \pm SEM $(n \geq 6)$ and analysed using 1-way ANOVA with Dunnett post-test or Students t-test. (\# $p<0.05$, \#\# $p<0.01$, \#\#\# $<<0.001$ vs control \& $* p<0.05$, $* * \mathrm{p}<0.01, * * * \mathrm{p}<0.001$,vs acrolein) 
R T 4
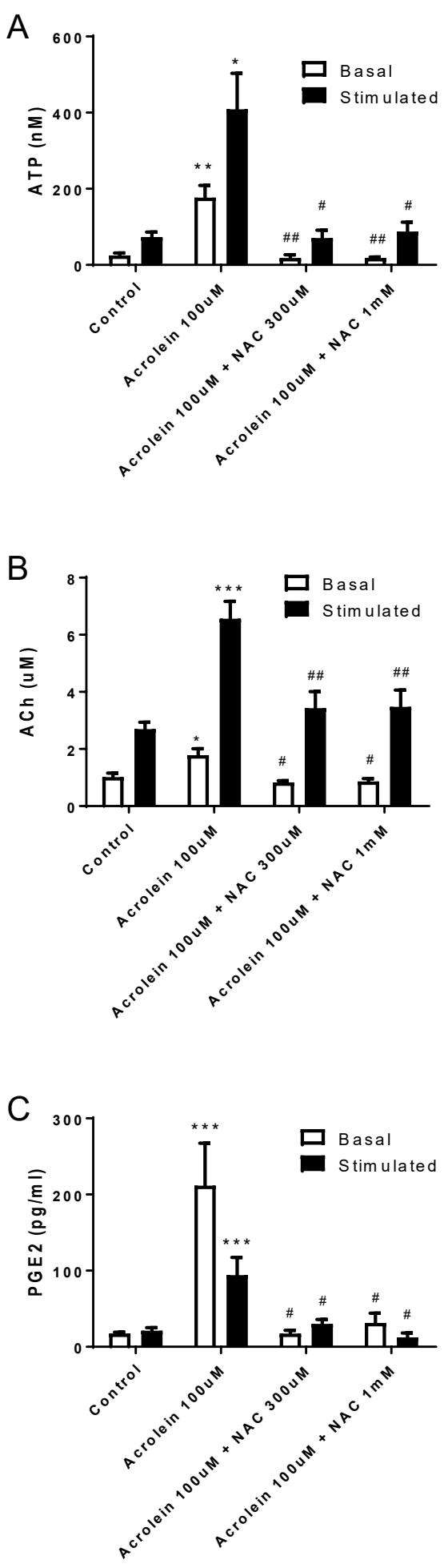

T 24
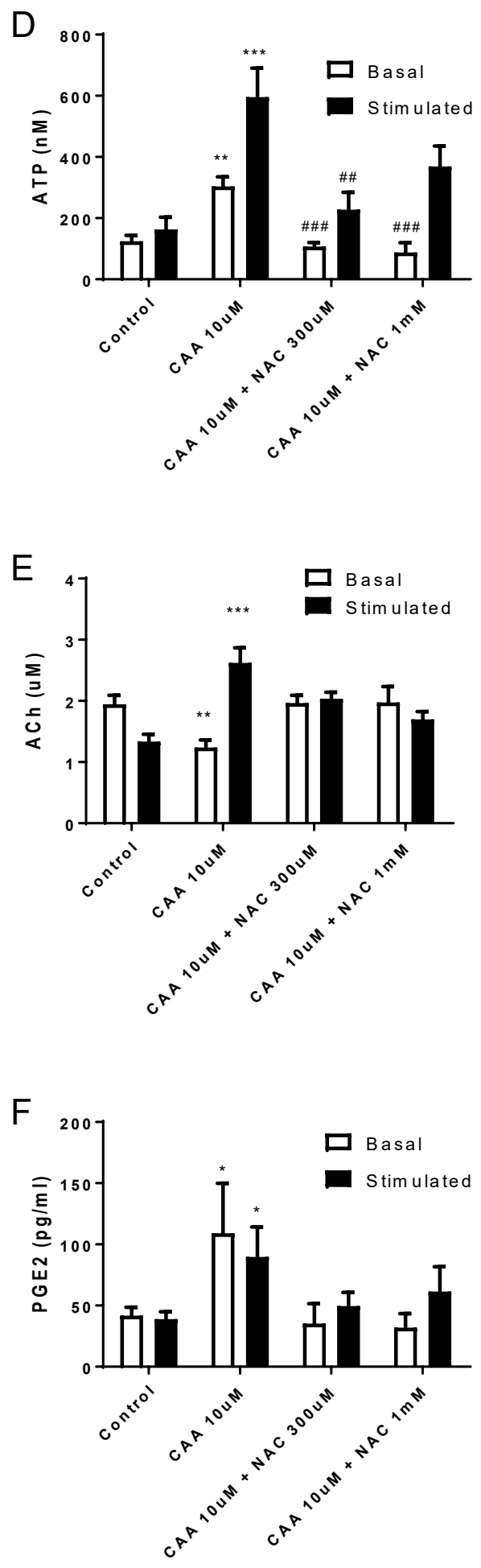

Fig. 5 Effect of 24 hour treatment with acrolein in RT4 (A-C) or CAA in T24 (D-F) cells on basal and hypo-osmotically stimulated ATP and acetylcholine and $\mathrm{PGE}_{2}$ levels in the absence and presence of NAC. Data are shown as mean \pm SEM $(n=6)$ and analysed using 1-way ANOVA with Dunnett post-test or Students t-test. (*vs control, \# vs acrolein or CAA in the absence of NAC) 